\title{
A defesa da escravidão no parlamento imperial brasileiro: 1831-1850
}

The fight for slavery in the Brazilian

Imperial Parliament: 1831-1850

\section{Tâmis Peixoto Parron}

Aluno de graduação em História da Faculdade de Filosofia, Letras e Ciências Humans da Universidade de São Paulo. Desenvolve pesquisa de Inciação Científica, com bolsa da FAPESP, sob orientação do Prof. Dr. Rafael de Bivar Marquese.

\section{Resumo}

Esse informe apresenta algumas das questões desenvolvidas em meu projeto de iniciação científica, sob o título de "A Defesa da Escravidão no Parlamento Imperial Brasileiro: 1831-1850", em que pesquiso os discursos sobre a escravidão, proferidos no Parlamento nas décadas de 1830 e 1840. Retomando a literatura sobre o assunto, que pouco trabalha a questão específica da defesa da escravidão no Brasil, e considerando os principais grupos políticos que emergiram na década de 1830, trato dos campos discursivos utilizados pela elite política imperial para defender a instituição do cativeiro.

\begin{abstract}
This text presents some of the questions I work with in my undergraduate research project, called "The fight for slavery in the Brazilian Imperial Parliament: 1831-1850", that focuses on the speeches concerning slavery made between 1831 and 1850 in the Brazilian Parliament. Reviewing the literature, that rarely handles specifically with the defenses of slavery in Brazil, and taking into account the main political groups that turned up in the 1830s, I search to delineate some rhetorical topoi common to the discourses of Brazilian politicians that tried to defend the institution of boundary.
\end{abstract}

Palavras-chave

poder legislativo, escravidão, Regência, debates parlamentares. Keywords

legislative power, slavery, Regency, parliamentary debates. 
1

Emilia Viotti da Costa. Da Senzala à Colônia. São Paulo: Difusão Européia do Livro, 1966. Octavio lanni. As Metamorfoses do Escravo. São Paulo: Difusão Européia do Livro, 1962. Fernando Henrique Cardoso. Capitalismo e Escravidão no Brasil Meridional. o Negro na Sociedade Escravocrata do Rio Grande do Sul. São Paulo: Difusão Européia do Livro, 1962. Florestan Fernandes. 0 negro no mundo dos brancos. São Paulo: Difel, 1971. Cf. também $A$ integração dos negros na sociedade de classes. 3a ed. São Paulo: Ática, 1978.

2

Emilia Viotti da Costa, op. cit., pp. 331-364.

Octavio lanni, op. cit., p.10.

Sidney Chalhoub. Visões da Liberdade - uma história das últimas décadas da escravidão na corte. São Paulo: Companhia das Letras, 2001, p. 122.
0 presente informe discute algumas das questões desenvolvidas em minha pesquisa de iniciação científica intitulada "A Defesa da Escravidão no Parlamento Imperial Brasileiro: 1831-1850". Meu objeto de estudo é a defesa da escravidão elaborada no Brasil desde a aprovação da primeira lei antitráfico até a passagem da lei Eusébio de Queiroz. Os objetivos, por sua vez, são fornecer subsidios para futuros estudos sobre emancipacionismo e pró-escravismo no Brasil Império e, sobretudo, delinear os topoi dos discursos políticos que fundamentaram as posições dos parlamentares frente à instituição do cativeiro.

Até o momento pude compulsar os Anais da Câmara dos Deputados entre 1831 e 1839 (disponiveis na Faculdade de Direito do Largo São Francisco) e os Anais do Senado de 1831, 1832, 1833 e 1837 (há que informar que as coleções dos Anais do Senado da Faculdade de Direito e do Arquivo do Estado de São Paulo são incompletas e, por isso, limitam o escopo de pesquisa nesta fase inicial dos estudos). Paralelamente, também tive acesso ao Acervo da Câmara dos Deputados e pude localizar um manuscrito composto em 1839 pela Assembléia Legislativa de Minas Gerais, que o havia enviado à Corte no momento justo em que se faziam as mais severas reservas à lei de 7 de novembro de 1831, responsável pelo fim legal do comércio de escravos africanos com o Brasil.

\section{Debate historiográfico}

São diversas as perspectivas metodológicas da historiografia que analisam a dinâmica da sociedade escravista no Brasil do século XIX. Dentre elas, pode-se destacar três que, de alguma forma, tocaram de tangente as defesas da escravidão. A mais antiga compreende as obras de Fernando Henrique e Octávio lanni, além dos primeiros livros de Emilia Viotti.1 Para esses autores, o que mais interessava eram as relações estruturais entre capitalismo e escravidão, cujas contradições levariam ao colapso do sistema escravista. Contemplando os cativos na condição de fatores de produção, todos entendiam que a sociedade escravista ao degradá-los, também os privava em grande medida de conformação intelectual e social própria. Nessa linha, não havia por que eleger a defesa da escravidão como eixo central de análise, uma vez que ela resultaria epifenômeno de um sistema fadado à destruição pelo capitalismo. Dai Emília Viotti fazer, em Da Senzala à Colônia (1966), um apanhado de juízos favoráveis à instituição a partir dos mais variados documentos - desde Vieira até as vésperas da abolição -, condensando em algumas páginas um panorama de três séculos de idéias escravistas. ${ }^{2}$ Considerava-se, antes, imprescindivel, para a "compreensão do sistema", o estudo das "atividades produtivas básicas", da exploração da mão-de-obra escrava e de sua substituição pelo trabalhador livre. ${ }^{3}$

A segunda perspectiva compõe-se de uma larga produção historiográfica que procurou dar voz à sociabilidade, à articulação familiar e à cultura dos escravos como domínio próprio, objetivando mostrar a responsabilidade que estes também tiveram sobre o desmantelamento da instituição. Nesse conjunto de obras, encontram-se, entre outros, os trabalhos de Célia Maria Marinho de Azevedo, Sidney Chalhoub e Eduardo Spiller Pena. Quando postos em pauta, o pensamento pró-escravista e a elite política imperial são predominantemente compreendidos e interpretados apenas a partir da pressão exercida pelas revoltas de escravos e pelos processos jurídicos que os envolvem. Em Visões da liberdade, Sidney Chalhoub chega a assinalar que "é possivel interpretar a lei de 28 de setembro [Ventre Livre], entre outras coisas, como exemplo de uma lei cujas disposições mais essenciais foram 'arrancadas' pelos escravos às classes proprietárias."4

A terceira perspectiva se caracteriza por voltar sua atenção, antes de tudo, sobre os golpes politicos e sociais que feriram de morte o sistema escravista. Os últimos anos da escravatura no Brasil, de Robert Conrad, e A 
Leslie Bethell. A Abolição do Tráfico de Escravos no Brasil: a Grã-Bretanha, o Brasil e a questão do tráfico de escravos, 18071869. Rio de Janeiro: Expressão e Cultura; São Paulo: Edusp, 1976. Robert Conrad. Os Últimos Anos da Escravatura no Brasil. Rio de Janeiro: Civilização Brasileira, 1978.

Jaime Rodrigues. 0 Infame Comércio Propostas e experiências no Final do Tráfico de Africanos para o Brasil (1800-1850). Campinas: Editora da Unicamp, 2000.

Idem, p. 211.
Abolição do Tráfico de Escravos no Brasil, de Leslie Bethell, são as produções mais significativas dessa terceira vertente..$^{5} \mathrm{Em}$ ambos os casos, a ênfase já não reside na estrutura econômica (comum à primeira perspectiva) nem nas lutas perpetradas pelos escravos (peculiar à segunda perspectiva), mas sim na campanha abolicionista, na pressão diplomática inglesa, nos jornais antiescravistas e nos debates parlamentares. Alguns dos argumentos pró-escravistas pronunciados nas assembléias parlamentares foram anotados pelos dois historiadores. Mas nenhum deles procurou entendê-los diacronicamente - ou seja, tais argumentos só foram recolhidos de periodos esparsos e como índices de lugares-comuns do pró-escravismo que em nada inovaria o que já fora dito alhures.

A Abolição do Tráfico de Escravos é bastante elucidativa em relação ao tratamento descontínuo dispensado às posturas pró-escravistas brasileiras. Interpretando o tráfico e o contrabando de escravos na primeira metade do século XIX, Leslie Bethell concentra seus esforços nos acordos assinados entre o Brasil e a Inglaterra (1817 e 1826), na política interna britânica, na orientação do Foreign Officer e, enfim, na coação da Grã-Bretanha sobre o Brasil por meio de seus embaixadores. Os expedientes brasileiros para prorrogar ao máximo as atividades do tráfico negreiro ou, em momentos de crise, torná-las ilegais o mais rápido possivel são apenas ocasionalmente referidos e, invariavelmente, ligados apenas a pressões externas. Noutros termos, as soluções e os projetos políticos brasileiros, quer pró-escravistas ou não - a distinção, aliás, é pouco sublinhada -, somente ganham forma na medida em que constituem respostas diretas aos estímulos, ameaças ou desafios, proporcionados pela política externa britânica. Bethell não procura, pois, compreendê-los à luz da lógica interna da política imperial brasileira.

Em cada uma dessas correntes, o "sujeito histórico" privilegiado foi, respectivamente, o sistema econômico, os escravos e as forças abolicionistas. De fato, a exceção a esses estudos é 0 Infame Comércio, de Jaime Rodrigues. 6 Nesse caso, o autor herda da segunda corrente a importância da agência escrava: os levantes dos cativos e a idéia pejorativa de povo, no imaginário da elite política imperial, teriam influenciado sobremaneira os parlamentares a pensar seriamente no fim do tráfico. Por outro lado, Jaime Rodrigues reconhece que a pressão inglesa (objeto da terceira linha) foi um "fator de aglutinação da elite política para que se chegasse a uma proposta consensual - e a partir de 1845, de execução rápida - para se acabar com o tráfico."7 Ao pluralizar as forças em atuação no campo da escravidão brasileira, Jaime Rodrigues reconstituiu - o que verdadeiramente importa para o presente texto - o papel do parlamento imperial no processo decisório sobre o futuro da instituição escravista.

No entanto, Jaime Rodrigues não fez desse o assunto central de seu livro e, assim, não percebeu como as propostas a favor da escravidão, encaminhadas em meados da década de 1830, se relacionavam com outras questões do aparelho do Estado brasileiro. Ademais, tampouco anotou a diacronia dos discursos a respeito da escravidão no decorrer da década de 1830. De fato, é possivel observar uma tendência que emerge após a lei de 1831 e dura até 1835, além de outra que, parte deste ano, desmembrando-se em duas direções até 1839, conforme será exposto mais adiante.

Todavia, não se havia tentado reconstituir a trajetória, em linha diacrônica, de grupos que defendiam a escravidão - como modo de vida, base da lavoura, fonte do Estado -, no sentido de entender a dinâmica do próprio sistema escravista. Ao fazê-lo, pude notar que o aumento das exportações do comércio lícito, o desenvolvimento da marinha nacional, o discurso da imoralidade ou do desrespeito às leis e a formação do estado nacional (nos niveis identitário e burocrático) andaram, lado a lado, com o trato negreiro durante a Regência. 
Quentin Skinner e James Tully (eds). Meaning and Context. Quentin Skinner and his Critics. Cambridge: Polity Press, 1988, pp. 29-67.

Idem, p. 56, grifos meus.

10

Terminologia de Reinhardt Koselleck. Futuro Pasado: para una Semántica de los Tiempos Históricos. Barcelona: Paidós, 1993, pp. 111112

11

Jaime Rodrigues, op. cit., p. 132.
Tentei reconstituir os discursos parlamentares sobre a escravidão, durante a Regência, por meio do "método contextualista" de Quentin Skinner e da idéia de "luta semântica" de Reinhardt Koselleck. Em "Meaning and Understanding in the History of Ideas", Skinner arrola formas de essencialismo e determinismo, as quais todo historiador se expõe quando realiza uma história das idéias. 8 De fato, seria tão fácil reconhecer o essencialismo quanto difícil evitá-lo. Principalmente porque, entre suas manifestações, uma das principais se liga exatamente à relação furtiva entre significado e uso, sentido geral e emprego particular, lugar-comum e ocorrência. Criticando o costume intelectual da utilização de fontes apenas como exemplos de repetições de idéias essencialmente invariáveis, Skinner alerta que não há de fato uma idéia-entidade à qual inúmeros autores se voltam, mas sim uma "variedade de declarações feitas com as palavras por uma variedade de agentes diferentes com uma variedade de intenções; então, o que estamos vendo é que não há uma história da idéia a ser escrita, mas apenas uma história necessariamente focada em vários agentes que usaram uma idéia, e nas variadas situações e intenções em usá-la."9 Torna-se, então, fundamental que o pesquisador tenha em mente uma série de preocupações: a que perguntas o uso de tal idéia quis responder? A quem exatamente se dirigiu? Que status tinha a idéia na época? Qual o arco de possibilidades o sujeito discursivo contemplava ao escolher aquela idéia? A análise do uso está, pois, intimamente relacionada com o estudo de grupos sociais (ou agentes) que se articulam em torno de determinados conceitos para construir sua própria imagem e denegrir as dos grupos conflitantes. Por isso, o método proposto por Skinner pode ser enriquecido com o conceito de "luta semântica" elaborado por H. Koselleck. Segundo o autor alemão, a "luta semântica" vigora em épocas de crises, nas quais se definem posturas políticas e posições de combate. Os lugares sociais de honra e recriminação, orgulho e vergonha, bazófia e infâmia se compõem e recompõem, então, em fluxo acelerado, no qual cada agente discursivo deve procurar novas maneiras de defender suas convicções antigas e selar como ignominiosas as dos opositores. 10

Tais métodos foram importantes para impedir eventuais desvios de interpretação. A historiografia refere-se, por exemplo, à idéia de que a "corrupção" provocada pela escravidão no Brasil constituía a bandeira dos homens hostis à instituição. Dessa maneira, referindo-se ao contrabando de africanos realizado após a lei de 1831, Jaime Rodrigues assinala que "um novo tipo de corrupção aparece aqui [após o início do contrabando]: a que teria se instalado entre as autoridades que eram coniventes com o tráfico. A persistência do comércio de africanos acentuava essa visão, ainda mais por não se retirar dele nenhum rendimento alfandegário e em função dos problemas existentes com o governo inglês. Voltavam-se para os traficantes os olhos supostamente moralizadores dos deputados e senadores, que não queriam se ver envolvidos diretamente na atividade".11 Essa afirmação, correta em sua generalidade, negligencia alguns aspectos importantes. Como veremos, o argumento da "corrupção" causada pelo contrabando foi utilizado, com muita veemência, pelos próprios defensores do tráfico de escravos, em debates que prepararam terreno para o Regresso e a centralização da máquina do Estado. Era, pois, um lugar-comum que os regressistas utilizaram com objetivo específico e interessado, mudando sensivelmente o significado apontado por Rodrigues. Por sua vez, graças ao conceito de "luta semântica" de Koselleck pude perceber como muitas falas contrárias ao comércio ilegal de africanos se forjaram, não em função da causa abolicionista em si, mas no interior de uma luta política pelos espaços do poder após a cisão entre os liberais moderados e, sobretudo, após a ascensão do Gabinete 19 de Setembro, em 1837, capitaneado pelo regressista Bernardo Pereira de Vasconcelos.

Por fim, cabe ainda uma observação sobre a existência ou não de uma ideologia escravista no Brasil. A principal conseqüência da lacuna historiográ- 
12

A respeito das convenções que proibiram o trato de escravos, ver Leslie Bethell, op. cit. e Jaime Rodrigues, op. cit. Sobre os impostos do período joanino vigentes à época da Independência, cf. Guilherme Deveza. "Política tributária no periodo imperial". In: Sérgio Buarque de Holanda (org.). História geral da civilização brasileira. Tomo II, $4^{\circ}$ vol., São Paulo: Difel, 1985, pp. 60-84.

13

Sobre a imposição do discurso cultural inglês, cf. João Pedro Marques. Os sons do silêncio: o Portugal do Oitocentos e a abolição do tráfico de escravos. Imprensa de Ciências Sociais, 1999,especialmente cap. 1. 0 autor faz um apanhado, fundamentalmente, dos textos de David Brion Davis. The problem of slavery in the age of Revolution, 1770-1823. New York: Oxford University Press, 1999 e de Howard Temperley. "Aboliton and anti-slavery: Britain". In: Seymour Drescher e Stanley L. Engermean (eds.). A historical guide to world slavery. New fica sobre defesas da escravidão no Império é a aceitação do pressuposto de que não teria havido, por aqui, pensamento pró-escravista nem, muito menos, ideologia da escravidão. Disso deriva outra conseqüência; a de que o entendimento da política escravista imperial, assim como de seus avanços e reveses, torna-se dependente, apenas, de campos explicativos exteriores (a economia, os conflitos sociais, o abolicionismo). A análise dos discursos pró-escravistas durante a Regência permitiu, contudo, perceber a existência de uma articulada prática escravista que envolveu o executivo, a câmara dos deputados, 0 senado, as câmaras municipais e, enfim, as assembléias provinciais. Às vezes, esses setores atuavam isoladamente, como o executivo e suas tentativas de incrementar o orçamento imperial a partir de 1836. Em outros momentos, agiam em concerto, como nas pressões, entre 1835 e 1839, sobre a revogação da lei de 1831. No momento em que todos agiram articuladamente, notase a construção de um campo conceitual comum em que os sujeitos sociais e políticos de diferentes regiões do país se esforçaram para convencer seus interlocutores na continuação do tráfico. Ora, a construção de um discurso que prima pela identificação social, e se realiza pelo esforço de persuasão de outrem, aproxima as ações pró-escravistas, de 1835 a 1839, do que se poderia chamar de "ideologia". No entanto, cumpre estudar a fundo as futuras articulações pró-escravistas, durante os anos de 1840, para acusar a tenacidade e a persistência do fenômeno.

\section{A herança de D. João VI e D. Pedro I: espaços para uma política da escravidão dentro de disputas políticas internas.}

Independente desde 1822, o Brasil não conquistou de imediato o reconhecimento de sua emancipação. Pelo contrário, teve de anuir a exigências de algumas potências européias a fim de figurar como um país soberano no concerto das nações civilizadas. Dentre as concessões mais importantes, duas se sobrelevam por interferirem, diretamente, nas finanças da recém-criada nação e na economia privada de seus cidadãos: o estabelecimento de tarifas alfandegárias reduzidíssimas para a importação de produtos e o fim do tráfico de escravos. De certa maneira, ambas as concessões constituiam a herança legada pela política de D. João VI, que teve de assinar com a Inglaterra os tratados de 1810, cujos conteúdos estipulavam, de um lado, o abatimento de impostos sobre manufaturados ingleses a 15\% e, de outro, o compromisso com a futura abolição do tráfico de escravos. ${ }^{12}$

0 legado português se fez sentir ainda em 1826, quando D. Pedro I convencionou com a Inglaterra o fim completo do trato negreiro, prevendo-o em três anos depois de sua ratificação. Reconhecido pela Coroa inglesa em 13 de março de 1827, esse tratado anglo-brasileiro passou a valer, a partir de 13 de março de 1830. Portanto, dessa data em diante, toda e qualquer pessoa que tentasse arrastar negros africanos para o Brasil seria julgada por uma comissão mista estabelecida em Serra Leoa.

Para a maioria dos parlamentares brasileiros da década de 1830, construir o Brasil não significava apenas seguir em frente com essa herança portuguesa. Mas ao invés, implicava re-significar os compromissos legados e reverter o jogo político em favor das partes supostamente lesadas, sobretudo, dos proprietários de escravos, dos traficantes e das finanças imperiais. No entanto, a Inglaterra havia deixado à disposição poucos espaços de manobra. No plano cultural, tinha imposto o discurso da filantropia e da humanidade, maculando com a pecha de "bárbaras" as nações que não o assimilassem; no plano político, legalizara as suas pretensões por meio de tratados reconhecidos por D. João VI e ratificados ou extremados por D. Pedro I quando o Brasil já era independente. ${ }^{13}$

Nesse quadro, as defesas escravistas, em uma novissima nação, não poderão ignorar os lugares-comuns da filantropia nem a legalidade das disposições aprovadas por um estado liberal. Isso significa que, no que se 
refere ao discurso, a defesa da escravidão terá de conviver com o respeito à humanidade e às leis nacionais. Quanto às práticas políticas, tudo aquilo a ser considerado justo e validamente possivel será feito: na impossibilidade de se importar legalmente africanos, estimulam-se as exportações de produtos lícitos para a África; na impossibilidade de suspender a vistoria em navios recém-chegados aos portos do Império, desmantela-se sistematicamente a força naval que poderia patrulhar a costa brasileira; na impossibilidade de anular o tratado de 1826 com a Inglaterra, tenta-se revogar a lei nacional de 1831 que liberta os africanos contrabandeados; na impossibilidade de se revogar essa mesma lei nacional, desregulamentam-se suas disposições mais severas, e assim por diante. 0 que se percebe é a existência de uma ativa "política da escravidão", intimamente ligada aos homens responsáveis pela construção e implantação do estado moderno e liberal no Brasil - Bernardo Pereira de Vasconcelos, Honório Hermeto Carneiro Leão, Diogo Antônio Feijó, Caldeira Brant (Marquês de Barbacena) e outros.

Mas a "política da escravidão" é uma categoria genérica que, ao abranger todas as práticas que defendiam a escravidão ou dela tiravam partido, deve ser perspectivada ao longo do decênio de 1830, conforme as ideologias políticas distintas que surgiram no desdobramento da Regência e os respectivos agentes históricos que nelas atuaram. Dessa maneira, foi possivel dividir, a partir das conversações parlamentares, o discurso sobre o tráfico e a "política da escravidão" em quatro manifestações: a primeira coincide com o momento "heróico" da abdicação de D. Pedro I, ou seja, com a "Revolução de 7 de Abril"; a segunda viceja no grande pacto que, selado pelos Liberais Moderados, culminaria com o Ato Adicional de 1834; a terceira surge dentro da articulação dos políticos conservadores que proporiam o "Regresso", isto é, a re-interpretação do Ato Adicional; e a quarta, enfim, surge como contrapartida da terceira e a ela se opõe. Cumpre, todavia, fazer um resumo de cada um desses momentos.

A primeira manifestação parlamentar sobre o tráfico, nos quadros da presente pesquisa, insere-se na conjuntura que se seguiu à abdicação de D. Pedro I. Pronunciadas apenas um mês após a "Revolução de 7 de Abril", as falas parlamentares dessa fase emanam de um contexto em que os ânimos politicos reafirmavam a soberania constitucional brasileira contra um tirano interno (D. Pedro I) e um agressor externo (a Inglaterra). Passava-se a impressão de que o Brasil privava das idéias filantrópicas e, espontaneamente, levaria a cabo a iníqua travessia atlântica por conta própria. Nesse momento de forte exaltação nacional e liberal, quando os revolucionários de 1831 pensavam que agiam contra a tirania à maneira dos ingleses de 1688, percebe-se sensivel tendência à desnacionalização dos traficantes, para coonestar as bases da soberania nacional, e de nacionalização das medidas antiescravistas, para repelir a imagem do Brasil como títere perverso conduzido por cordões filantrópicos pendentes de mãos inglesas. Em contrapartida, os brasileiros só são citados como vítimas potenciais do tribunal que, misto e estrangeiro, resulta injusto e ilegítimo. Não é de modo distinto que Cunha Mattos termina sua intervenção lembrando "o monstruoso artigo do tratado a este respeito, que expunha os cidadãos brasileiros a serem julgados e sofrer penas de um tribunal estrangeiro, artigo que fora muito censurado e que ele

York: Oxford University Press, 1998.

14

Anais da Câmara dos Deputados, ACD, 13 de orador não sabia por que fatalidade havia caído no esquecimento." 14

Logo em seguida, porém, tornou-se público o que já era óbvio: o tráfico não seria tão facilmente debelado. A primeira acusação, nesse sentido, parte de Miguel Calmon já em 1832: não apenas traficantes levados pela auri sacra fames corroíam as disposições de 1831, mas até "autoridades há que passam na opinião geral, não como coniventes, mas interessados neste comércio abominável". Contra esse horror, o presidente da província - extensão do governo central, pois, por ele designado - teria lutado com todo o "calor, interesse e energia que the são próprios quando se trata de promover o 
bem público (muitos apoiados)".15 A declaração de Calmon é a primeira a mencionar a "desmoralização do povo" por força do desrespeito à lei de 1831, que deveria ser reforçada para proibir a contento o odioso comércio. Nesse sentido, as acusações polarizaram a corrupta e viciosa Sociedade, de um lado, e o diáfano e impoluto Estado, de outro. Essa tendência perdura incólume de 1832 até 1835 e, de fato, coincide com o momento em que os liberais moderados permaneceram unidos. Quando, em 1835, deputados conservadores começam a retirar o apoio a Feijó, duas novas formas de discurso emergem vagarosamente, tirando a razão de ser desse segundo tipo de discurso.

Uma dessas formas é a que gira na órbita dos grupos francamente pró-escravistas. Os seus discursos sobre o tráfico derivam, na verdade, da reacomodação ideológica do discurso anterior. 0 Estado continua incólume e imaculado. Da mesma maneira, os traficantes continuam a ser alvejados. Entretanto, em vez de se chamar atenção para as prevaricações das autoridades locais ou de se arquitetar meios para reforçar a lei de 1831, como diziam querer inúmeros liberais moderados, volta-se a mira contra o maléfico teor da mesma lei, a saber, o de açular a imoralidade e o desrespeito às disposições burocráticas e legais do Estado. No lugar da inaplicação da lei, a sua inaplicabilidade. Outra novidade desse discurso: lavava-se a todo custo a imagem santificada dos proprietários. Esse tipo de reformulação do segundo discurso começa em 1835 e continua até o momento estudado, 1839. Coincide, pois, com a articulação dos deputados conservadores que começavam a engrossar o coro dos oposicionistas aos liberais moderados e empreenderiam, em 1837, o Regresso, a fim de reinterpretar o Ato Adicional de 1834.

A última forma analisada é a outra face da moeda, que também emerge do segundo tipo de discurso e, principalmente, como reação às práticas e idéias pró-escravistas, bem como à política centralizadora do Regresso. Assim, esse discurso se faz sentir, primeiro, a partir do momento em que o Gabinete 19 de Setembro ascende e, sobretudo, depois de sua queda em 1839. Dessa vez, de acordo com essas falas, o próprio Estado sentou-se no banco dos réus e teve de responder às críticas de cumplicidade com o tráfico, já que os liberais moderados se valiam dos tópicos relacionados ao tráfico negreiro ilegal para invectivar frontalmente seus inimigos politicos. Acresce, contudo, notar que práticas da política da escravidão também foram encampadas por tais liberais moderados, quando estiveram no poder com a ascensão do Gabinete de 12 de outubro de 1835.

Localizar e designar os tipos de discurso acerca da escravidão resulta útil porque, em primeiro lugar, confere historicidade às defesas escravistas, revelando o que as tornava verossímeis ou defensáveis, em certa conjuntura, e impensáveis ou irrealizáveis, em outra. Em segundo lugar, porque revela a articulação das idéias e práticas em torno da escravidão com as lutas pelos espaços do poder. Desse modo, as atitudes escravistas ou as posturas abolicionistas deixam de ser tomadas a priori, para serem analisadas em processos de formação, mudança e construção. Enfim, em terceiro lugar, porque evidencia a existência de um campo conceitual comum em que certas idéias são usadas tanto por um grupo como por outro - caso da corrupção dos costumes. Assim, mesmo que pressões vindas indiretamente de ações escravas (como o Haiti e o medo da haitianização) forjassem alguns conceitos, isso não quer dizer que a elite politica imperial tenha se colocado passivamente perante eles. Muito pelo contrário, empregou-os à maneira que Ihe convinha e era possivel, como, aliás, a qualquer agente histórico de seus próprios interesses.

\section{Desenvolvimento da pesquisa}

A continuidade desta pesquisa prevê a análise dos Anais da Câmara dos Deputados e dos Senadores até o ano de 1850. Além do que foi apresentado neste informe, venho também coletando significativo repertório de práticas políticas que protegiam o tráfico de escravos ou se beneficiavam dele. Pretendo, 
assim, adotar o mesmo critério analítico para a década de 1840: delinear os campos discursivos, nos quais se impreca contra a escravidão ou se lança em sua defesa (cujo correspondente para os anos de 1830 foi sintetizado nesta apresentação), paralelamente às práticas que permitiam a continuidade do tráfico de escravos. 